\title{
UN SISTEMA LINEAL DE GASTO: IDENTIFICANDO PATRONES DE CONSUMO DE ALIMENTOS EN BOLIVIA
}

\section{Cristian Ricardo Nogales Carvajal}

\section{RESUMEN}

El presente estudio aborda la identificación de patrones consumo, partiendo de una revisión teórica de las particularidades de las preferencias individuales subyacentes en el Sistema Lineal de Gasto (LES). Se describe, explica e implementa un método de estimación del Sistema por Máxima de Verosimilitud propuesto por Kao, Lee \& Pitt (2001). Para facilitar la estimación, el método contempla la simulación de la parte de la función de verosimilitud que toma en cuenta de manera explícita la ausencia de consumo de algunos bienes por parte de algunos hogares. Para enriquecer el Sistema, el método permite incluir variables sociodemográficas susceptibles de determinar los patrones de consumo. Este método es aplicado al estudio de patrones de consumo en Bolivia, diferenciados de acuerdo a la zona geográfica: llanos, altiplanos y valles. De manera general, se encuentra que los hogares bolivianos prefieren los alimentos que presentan un grado de elaboración intermedia. Se constata, entre otros resultados importantes, que este tipo de bienes presentan una sensibilidad relativamente alta a cambios en sus precios, el ingreso de los hogares y los precios del resto de los alimentos.

Palabras Clave: Sistema Lineal de Gasto, Máximo de Verosimilitud, Elasticidad Ingreso, Elasticidad precio Directa, Elasticidad Precio Cruzada. 